\title{
CARACTERIZACION DE Pleurotus Sp. AISLADO DE LA COMUNIDAD NATIVA DE KORIMANI, CENTRO POBLADO DE KITENI-ECHARATE, LA CONVENCION, CUSCO, PERÚ
}

\section{CHARACTERIZATION OF Pleurotus sp. ISOLATED FROM KORIMANI NATIVE COMMUNITY, KITENI-ECHARATE TOWN CENTER, LA CONVENCION, CUSCO, PERU}

\author{
Fraido Aguilar-Pumahuillca ${ }^{1}$, Hermes Huamán-Huamán² y María Holgado-Rojas ${ }^{3}$
}

\section{Resumen}

El presente trabajo de investigación se realizó con la finalidad de caracterizar la cepa silvestre de Pleurotus sp. colectada en la comunidad nativa de Korimani, para conocer sus cualidades, puesta en valor e introducción a la biotecnología del cultivo de hongos utilizando sustratos locales como alternativa alimentaria y productiva. La cepa se aisló a partir del pseudotejido de los cuerpos fructíferos en cuatro medios de cultivo sólidos, Agar Papa Dextrosa (PDA), Agar Arroz (AA), Agar Papa Zanahoria (APZ) y Agar Camote (AC). Estadísticamente los cuatro medios de cultivo fueron óptimos para la propagación vegetativa del micelio a una temperatura de $25^{\circ} \mathrm{C}$ con una TCD (Tasa de Crecimiento Diario) de $1.1 \mathrm{~cm} /$ día codificándose como d027-CIPHAM. Los basidiomas correspondieron a la especie Pleurotus djamor (Rumph. ex Fr.) Boedijn. El cultivo se realizó en residuos lignocelulósicos propios de la zona, hojas de plátano (Musa sp.) y rastrojo de trigo (Triticum aestivum) incubados a $25^{\circ} \mathrm{C}$ obteniéndose cuerpos fructíferos a los 7 días después de la inducción a la fructificación bajo condiciones controladas de laboratorio. De acuerdo al análisis físicoquímico realizado, $P$. djamor presenta $19.46 \%$ de proteínas y $57.31 \%$ de carbohidratos, convirtiéndose en un recurso genético fúngico promisorio para la región Cusco.

Palabras clave: caracterización, Pleurotus, promisorio, Korimani, Cusco.

\begin{abstract}
The present research work was carried out with the purpose of characterizing the wild strain of Pleurotus sp. collected in the native community of Korimani, in order to assess its qualities, value and its introduction to the mushroom cultivation biotechnology, using local substrates as a nutritional and productive alternative. The strain was isolated from pseudo-tissue of the fruiting bodies in four solid culture media: Potato Dextrose Agar (PDA), Rice Agar (AA), Potato Carrot Agar (APZ) and Sweet potato Agar (AC). Statistically, the four culture media were optimal for the vegetative propagation of the mycelium at a temperature of $25^{\circ} \mathrm{C}$ with a daily growth rate (DGR) of $1.1 \mathrm{~cm}$ / day coding as d027-CIPHAM. The basidiomas collected corresponded to the species of Pleurotus djamor (Rumph. ex Fr.) Boedijn. The culture was carried out in local lignocellulosic residues, banana leaves (Musa sp.) and wheat stubble (Triticum aestivum) incubated at $25^{\circ} \mathrm{C}$, obtaining fruit bodies at 7 days after induction under controlled laboratory conditions. According to the physical-chemical analysis carried out, $P$. djamor presents $19.46 \%$ of proteins and $57.31 \%$ of carbohydrates, becoming a promising fungal genetic resource for the Cusco region.
\end{abstract}

Key words: characterization, Pleurotus, promising, Korimani, Cusco.

\section{Introducción}

El género Pleurotus está constituido por diversas especies comestibles que son cultivadas experimental y comercialmente en diferentes regiones del mundo. La definición taxonómica de las especies y la validez de los nombres asignados es un tema muy discutido, que se ha abordado morfológica, genética y molecularmente, sin que se hayan logrado aún conclusiones completamente consensuadas. De las aproximadamente 50 especies válidas taxonómicamente para el género, al menos 12 han sido cultivadas, entre las que $P$. ostreatus, $P$. pulmonarius, $P$. eryngii y $P$. djamor son las de mayor importancia comercial (Salmones \& Mata 2017).

Es importante destacar que el conocimiento de la diversidad genética del género Pleurotus y la adecuada preservación de su germoplasma constituyen un reto para la industria del cultivo de hongos, pero a la vez, una oportunidad de acceder a nuevas cepas, genes y enzimas de interés para la optimización de los procesos 
existentes, así como para el desarrollo de nuevos productos de interés biotecnológico (Salmones \& Mata 2017), siendo uno de los valores más importantes de una colección de cepas la diversidad geográfica y ecológica de su germoplasma, ya que las poblaciones silvestres son el recurso más importante para la diversidad requerida por el sector productivo de los hongos cultivados (Salmones \& Mata, 2013)

El cultivo de hongos comestibles en la actualidad se presenta como una alternativa ideal para la obtención de alimentos, sobre todo en países con economías emergentes. El desarrollo de este tipo de tecnologías requiere del aislamiento y evaluación del crecimiento micelial de las especies reportadas como comestibles para promover su cultivo bajo condiciones locales. Pleurotus spp. es uno de los grupos más importantes de hongos comestibles cultivados comercialmente, posicionándose en el segundo lugar a nivel mundial. El 99\% de la producción de Pleurotus se concentra en el continente asiático, especialmente en China. En Latinoamérica, la producción comercial se genera mayoritariamente en Brasil, México, Colombia, Argentina y Guatemala (Royse \& Sánchez, 2017). Por otro lado, los bosques de la comunidad nativa de Korimani albergan una gran diversidad de macrohongos aún no determinados que pueden ser utilizados en la alimentación por los pobladores, entre ellos especies del género Pleurotus, que poco o nada se aprovechan a pesar de su alto contenido proteico, además que en la comunidad también se producen residuos de café, achiote, cacao y plátano que pueden servir de sustrato para el cultivo de estos hongos, por lo que en la presente investigación realizamos la caracterización de la cepa silvestre de Pleurotus sp. en cuatro medios de cultivo sólidos con el fin de conocer el medio de cultivo óptimo para el crecimiento miceliar y lograr cuerpos fructíferos en residuos lignocelulósicos generados en la zona, contribuyendo de esta manera al desarrollo y fortalecimiento de la fungicultura en la región.

\section{Materiales y métodos}

Ubicación Geográfica

El Centro Poblado de Kiteni se ubica en la zona Nor-Oeste del Distrito de Echarati, Provincia de la Convención, Región Cusco. Latitud Sur: 12 38' 52.9" Longitud Oeste: $73^{\circ}$ 02' 53.7", 605 msnm. El clima es tropical y está marcado por dos estaciones: lluvias y secas; la época de lluvias ocurre entre los meses de octubre a mayo con una temperatura media anual de $24.8^{\circ} \mathrm{C}$ y una precipitación pluvial de $1457 \mathrm{~mm}$ al año.

\section{Metodología}

\section{Colecta de basidiocarpos}

Los basidiocarpos se colectaron en época de lluvias obteniendo aquellos que presentaron las mejores características en cuanto al tamaño, aspecto y textura, los cuales fueron extraídos de su hábitat con la ayuda de una navaja y colocados en frascos de vidrio estériles para ser transportados al laboratorio para su respectiva descripción y aislamiento. La descripción macroscópica y microscópica se realizó utilizando bibliografía especializada y consulta a especialistas tomando en cuenta el tamaño del píleo, estípite, color, forma y tamaño de las esporas, basidios y micelio.

Obtención de la cepa y preparación del inóculo fúngico ("semilla")

Para la obtención de la cepa de Pleurotus sp. se seleccionaron los carpóforos considerando el tamaño y el grado de desarrollo, preferentemente los juveniles con buenas características organolépticas, (Saldarriaga $\&$ Pineda, 2001). Se realizaron cortes de $0.4-0.5 \mathrm{~cm}$ del pseudotejido siendo colocados en placas de Petri con medios de cultivo Papa Dextrosa Agar (PDA), Agar Arroz (AA), Agar Papa Zanahoria (APZ) y Agar Camote (AC) e incubados a $25{ }^{\circ} \mathrm{C}$. El crecimiento y características morfológicas de los micelios se evaluaron cada 24 horas registrando el diámetro del micelio en dos ejes cartesianos trazados sobre las tapas de las placas para determinar la tasa de crecimiento diario (TCD). La evaluación se realizó durante siete días, tiempo en el cual el micelio invadió completamente las cajas. (Figura 4).

La preparación del inoculo fúngico ("semilla") se realizó en una cámara de flujo laminar utilizando granos de trigo como vehículo de aumento de biomasa. Se colocó fragmentos de $1 \mathrm{~cm}^{2}$ de agar con micelio en bolsas de polipropileno que contenían los granos de trigo estériles, las bolsas inoculadas se incubaron a 25 ${ }^{\circ} \mathrm{C}$.

Determinación de la tasa de crecimiento diaria

Para el cálculo de la TCD se usó la siguiente formula (Martínez, 1993):

Donde:

$$
T C D=\frac{D_{f}-D_{i}}{T}
$$

TCD: Tasa de crecimiento diario

$\boldsymbol{D}_{\boldsymbol{f}} \quad$ : Diámetro final de la colonia

$\boldsymbol{D}_{\boldsymbol{i}} \quad$ : Diámetro inicial de la colonia

T : Tiempo total de crecimiento micelial

\section{Tratamiento Estadístico}

Las TCD obtenidas para cada medio de cultivo fueron sometidas al análisis de varianza (ANOVA). Esta prueba permite observar y afirmar la existencia o no de diferencias significativas entre los promedios de las repeticiones para cada tratamiento. Para cuyo objetivo se planteó una hipótesis nula $\left(\mathrm{H}_{0}\right)$ : todos los tratamientos tiene medias iguales; y una hipótesis alterna $\left(\mathrm{H}_{1}\right)$ : al menos un par de tratamientos no tiene medias iguales (Wayne, 2012).
$\mathrm{H}_{0}: \overline{X 1}=\overline{X 2}=\overline{X 3}=\overline{X 4}$
$\mathrm{H}_{1}$ : No todas $\overline{\boldsymbol{X n}}$ son iguales 
Cultivo de Pleurotus en sustratos lignocelulósicos (Musa sp., Triticum aestivum)

Como sustrato final para el desarrollo de los basidiomas se utilizaron residuos de Musa sp., y Triticum aestivum fragmentados mecánicamente en pedazos de 1-3 centímetros sometiéndolos a un pretratamiento mediante pasteurización en agua caliente a $80{ }^{\circ} \mathrm{C}$ durante una hora (Buswell et al., 1993). Se procedió a la inoculación y embolsado del sustrato en condiciones asépticas para evitar la presencia de contaminantes ambientales. La incubación se realizó a $25^{\circ} \mathrm{C}$ durante 7 y 9 días hasta la invasión completa del micelio. Culminada la incubación, los sustratos fueron inducidos a fructificar cambiando las condiciones ambientales: presencia de luz utilizando lámparas fluorescentes de 3 a 4 horas/día, humedad relativa de $67 \%$ - 82\% mediante riegos dos veces al día, temperatura entre $21^{\circ} \mathrm{C}-23^{\circ} \mathrm{C}$ con una aireación de 30 minutos utilizando ventiladores caseros.

\section{Resultados y discusión}

Posición taxonómica de Pleurotus sp.

\begin{tabular}{cl}
\multicolumn{1}{c}{ Reino: } & Fungi \\
División: & Eumycota \\
Subdivisión: & Basidiomicotina \\
Clase: & Holobasidiomycetes \\
Subclase: & Hymenomycetidae \\
Orden: & Agaricales \\
Familia: & Pleurotaceae \\
Género: & Pleurotus
\end{tabular}

Especie: Pleurotus djamor (Rumph. ex Fr.) Boedijn (1959)

Nombre vernacular: pecho de gallina.

Codificación de la cepa: d027-CIPHAM.

Descripción macroscópica de los basidiocarpos

Pleurotus djamor es un basidiomicete de hábitat lignícola, gregario, con basidiocarpos sésiles y moderadamente adherido al sustrato (Figura 1). Píleo de 9 a $15 \mathrm{~cm}$ de ancho, borde lobulado, consistencia carnosa, superficie lisa de color rosado intenso, lamelas decurrentes, juntas, delgadas y bifurcadas con el borde liso. Estípite lateral muy corto, micelio de color blanco que al madurar se torna algodonoso. Esporas de color rosado intenso (Figura 2).

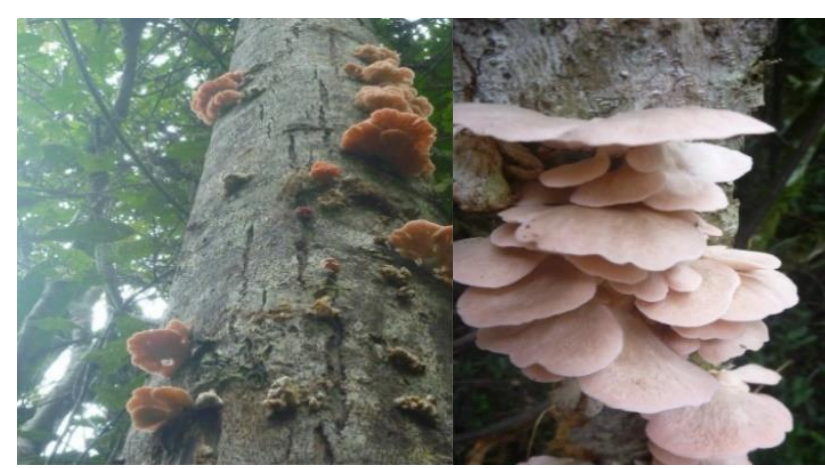

Figura 1. Pleurotus djamor in situ.

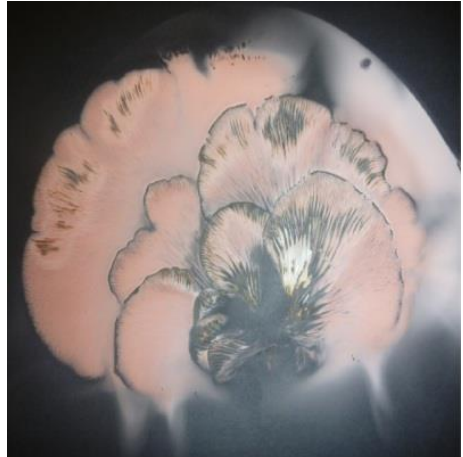

Figura 2. Esporada de Pleurotus djamor.

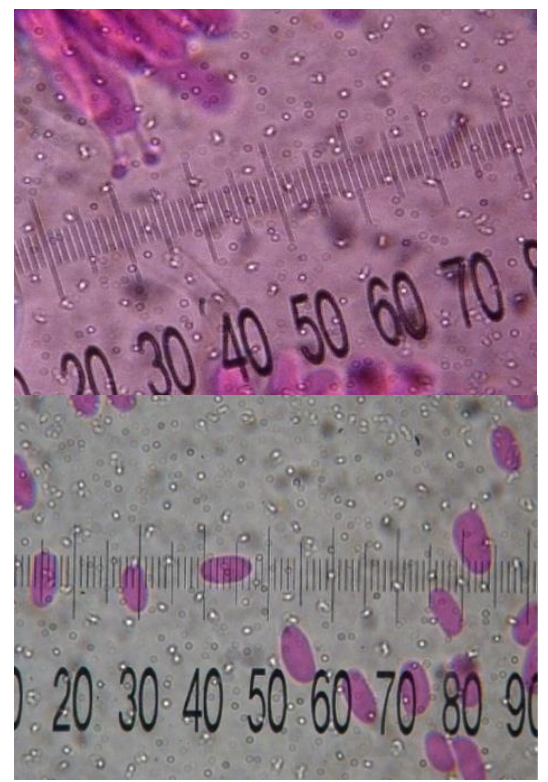

Figura 3. Basidios y basidiosporas de Pleurotus djamor con reactivo floxina.

De acuerdo con Pegler (1977, 1983, 1986), Guzmán (2000) y Nicholl \& Petersen (2000), P. djamor es la especie pantropical más importante y abundante del género Pleurotus. Fue originalmente descrito por Rumph en 1750 en Herbarium Amboinense bajo el nombre de Boletus secundus arboreus, el autor describió al hongo en forma de hígado, mostrando una coloración rojiza cuando joven, desvaneciéndose a blanco, amarillo mate o amarillento en su madurez.

El epíteto de la especie fue sancionado por Fries en 1821 como Agaricus djamor de la tribu Pleurotus, subtribu Concharia y en 1836, lo traslado al género Lentinus, posteriormente Boedijn en 1959 transfirió el epíteto al género Pleurotus de la familia Pleurotaceae (Nicholl \& Peterson, 2000).

Corner (1981) observó una amplia variabilidad micromorfológica entre especímenes provenientes de Malasia, determinando que esta especie podría clasificarse en seis variedades de acuerdo con su variabilidad en color, micromorfología y hábitat. 
Tabla 1. Tasa de Crecimiento Diario del micelio de $P$. djamor en cuatro medios de cultivo a $25{ }^{\circ} \mathrm{C}$.

\begin{tabular}{|c|c|c|c|c|c|c|c|c|c|c|c|c|c|c|c|c|c|c|c|c|c|c|c|c|c|}
\hline \multirow{2}{*}{\multicolumn{2}{|c|}{$\begin{array}{c}\text { MEDIO } \\
\text { REP. }\end{array}$}} & \multicolumn{5}{|c|}{ PDA } & \multirow{2}{*}{$\sum_{0}^{\infty}$} & \multicolumn{5}{|c|}{ AA } & \multirow{2}{*}{$\sum_{0}^{\infty}$} & \multicolumn{5}{|c|}{$\mathrm{APZ}$} & \multirow{2}{*}{$\underset{8}{2}$} & \multicolumn{5}{|c|}{$\mathrm{AC}$} & \multirow{2}{*}{ 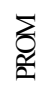 } \\
\hline & & 1 & 2 & 3 & 4 & 5 & & 1 & 2 & 3 & 4 & 5 & & 1 & 2 & 3 & 4 & 5 & & 1 & 2 & 3 & 4 & 5 & \\
\hline & 1 & 0.48 & 0.49 & 0.31 & 0.21 & 0.46 & 0.39 & 0.47 & 0.25 & 0.44 & 02 & 0.37 & 0.35 & 0.56 & 0.6 & 0.6 & 0.44 & 0.34 & 0.51 & 0.26 & 0.5 & 0.31 & & & 0.39 \\
\hline & 2 & 0.08 & 0.54 & 0.38 & 0.64 & 027 & 0.38 & 0.63 & 0.96 & 0.54 & 0.79 & 0.83 & 0.75 & 1.3 & 0.64 & 12 & 4 & 1.09 & 1.05 & 0.5 & 0.91 & 0.5 & 45 & & 0.55 \\
\hline $\mathrm{T}$ & 3 & 1.41 & 121 & 13 & 0.75 & 0.74 & 1.08 & 0.86 & 0.92 & 0.65 & 0.88 & 1.12 & 0.89 & 13 & 131 & 0.95 & 1.06 & 1.31 & 1.19 & 1.25 & 13 & 0.85 & 1.08 & 1.36 & 1.17 \\
\hline $\mathrm{C}$ & 4 & 1.88 & 1.44 & 1.89 & 1.67 & 1.94 & 1.76 & 1.12 & 0.49 & 0.96 & 1.09 & 2.05 & 1.14 & 1.6 & 1.85 & 0.87 & 097 & 1.49 & 136 & 1.28 & 2.47 & 1.23 & 1.1 & 0.86 & 139 \\
\hline \multirow[t]{2}{*}{ D } & 5 & 1.24 & 1.12 & 139 & 129 & 2.46 & 1.50 & 0.86 & 2.83 & 2.78 & 2.1 & 098 & 191 & 0.87 & 1.12 & 1.58 & 1.25 & 094 & 1.15 & 1.45 & 1.89 & 126 & 2.08 & 225 & 1.79 \\
\hline & 6 & 1.45 & 1.23 & 1.46 & 1.36 & 1.28 & 1.36 & 23 & 1.62 & 097 & 1.05 & 1.1 & 1.41 & 1.1 & 133 & 1.17 & 1.09 & 1.27 & 1.19 & 1.6 & 0.44 & 1.47 & 1.57 & 1.71 & 136 \\
\hline \multicolumn{2}{|c|}{ PROM. } & 1.18 & 1.06 & 1.15 & 1.15 & 1.16 & 1.14 & 1.14 & 1.14 & 1.06 & 1.06 & 1.06 & 1.09 & 1.1 & 1.1 & 1.1 & 1.12 & 1.1 & 1.10 & 1.13 & 1.4 & 1.08 & 1.12 & 1.12 & 1.12 \\
\hline
\end{tabular}

Guzmán et al., (1993) también notaron diferencias de coloración en los píleos desde blanquecino a grisáceo o rosáceo, proponiendo una posible sinonimia con otras especies de Pleurotus, como P. salmoneostramineus y $P$. ostreatoroseus, paralelamente Petersen \& Hughes (1993) encontraron que $P$. ostreatoroseus y $P$. salmoneostramineus eran genéticamente compatibles. Guzmán et al. (1995) describieron tres variedades ecológicas en la especie: P. djamor (Fr.) Boedijn var. djamor, caracterizada por desarrollar primordios y basidiomas blanquecinos; $P$. djamor var. roseus Corner, que presenta primordios de color rosa y/o naranja disminuyendo su coloración en estado adulto y P. djamor var. salmoneostramineus (L. Vass) Guzmán, que se distingue por presentar primordios y basidiomas adultos de color rosa y/o naranja. Posteriormente Guzmán (2000), consideró que $P$. djamor es sinónimo de $P$. flabellatus, $P$. eous y P. salmoneostramineus. Cultivo de Pleurotus djamor

\section{Aislamiento a partir de pseudotejido}
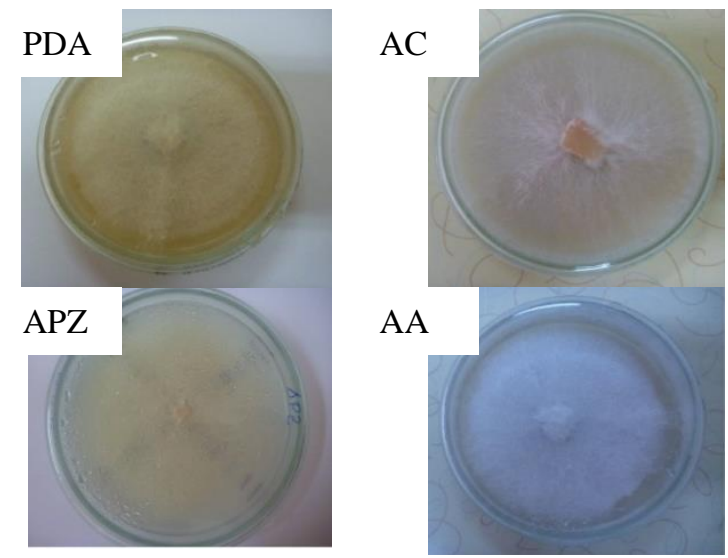

PDA: Papa Dextrosa Agar; AC: Agar Camote; APZ: Agar Papa Zanahoria; AA: Agar Arroz.

Figura 4. Crecimiento micelial, en medios de cultivo solidos PDA, AC, APZ y AA.

\section{Tasa de Crecimiento Diario (TCD)}

El crecimiento micelial de Pleurotus djamor fue favorable en los 4 medios de cultivo sólidos (Tabla 1). En la Figura 5 podemos observar que no existen diferencias significativas entre ellos presentando tasas de crecimiento diario de $1.14,1.09,1.10$ y 1.11 , respectivamente, comparando estos resultados con lo obtenido por Holgado (2012) quien reporta una tasa de crecimiento de $0.61 \mathrm{~cm} /$ día en medio de cultivo MBC para $P$. djamor y Aguilar (2014) que reporta el crecimiento de $0.97 \mathrm{~cm} /$ día para $P$. eryngii podemos ver que $P$. djamor aislado de la comunidad de Korimani es un cepa precoz invadiendo los medios de cultivo en solo 7 días con una TCD de $1.1 \mathrm{~cm} /$ día. La cepa obtenida fue codificada como d-027-CIPHAM.

Los resultados fueron analizados mediante prueba ANOVA y Tukey, para determinar la significancia estadística entre los medios de cultivo, (Tablas 2 y 3 ), si bien existe diferencias de la TCD entre los medios de cultivo comerciales (PDA) y alternativos (AA, APZ, AC) estas no son relevantes, por lo que $P$. djamor procedente de la comunidad nativa de Korimani es un basidiomicete que se puede adaptar a diferentes medios de cultivo sin variar sustancialmente sus condiciones de precocidad.

Tabla 2. Prueba de ANOVA para la Tasa de Crecimiento Diario.

\begin{tabular}{lccccc}
\hline & $\begin{array}{c}\text { Suma de } \\
\text { cuadrados }\end{array}$ & gl & $\begin{array}{c}\text { Media } \\
\text { cuadrática }\end{array}$ & F & Sig. \\
\hline $\begin{array}{l}\text { Entre } \\
\text { grupos }\end{array}$ & 0.006 & 3 & 0.002 & 1.373 & 0.287 \\
$\begin{array}{l}\text { Dentro de } \\
\text { grupos }\end{array}$ & 0.024 & 16 & 0.002 & & \\
Total & 0.031 & 19 & & & \\
\hline
\end{tabular}

Tabla 3. Resumen de la prueba post hoc de Tukey para la TCD.

\begin{tabular}{lll}
\multicolumn{2}{l}{ MEDIO DE } & \multicolumn{2}{c}{ Subconjunto para alfa $=0.05$} \\
CULTIVO & $\mathrm{N}$ & 1 \\
\hline AA & 5 & 1.0920 \\
APZ & 5 & 1.1040 \\
AC & 5 & 1.1080 \\
PDA & 5 & 1.1400 \\
Sig. & & 0.251 \\
\hline
\end{tabular}

\section{Obtención de los basidiomas de Pleurotus djamor}

Los cuerpos fructíferos de $P$. djamor se desarrollaron en 14 y 18 días utilizando hojas de Musa sp. y rastrojo de Triticum aestivum respectivamente (Figura 6), comparando con Holgado (2012) quien reporta ciclos de producción de 47 días en rastrojo de trigo podemos ver que la cepa d-027-CIPHAM es bastante precoz. Además, esta capacidad del hongo 


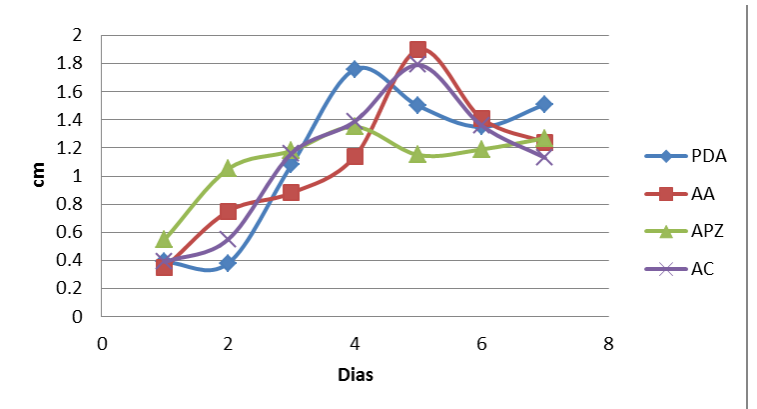

PDA: Papa Dextrosa Agar; AA: Agar Arroz; APZ: Agar Papa Zanahoria; AC: Agar Camote.

Figura 5. Desarrollo del micelio de $P$. djamor en diferentes medios de cultivo.

para colonizar el sustrato en tiempos cortos de incubación, le da ventaja competitiva ante la presencia de mohos antagonistas, frecuentemente presentes en las diferentes etapas del proceso de cultivo (Salmones \& Mata, 2015).

Valor Nutricional de Pleurotus djamor

Los cuerpos fructíferos de $P$. djamor obtenidos en sustrato de Musa sp. presentaron $19.46 \%$ de proteínas (Tabla 4), estos valores proteínicos son similares al de otras especies de hongos comestibles, así Agaricus presenta 19\%, Amanita caesarea 13\%, Boletus edulis $18.5 \%$, especies que se encuentran entre las más cotizadas para el consumo humano (Cano \& Romero, 2016). En general los hongos del genero Pleurotus presentan una calidad de proteína alta, ya que está constituida principalmente por aminoácidos esenciales entre los que destacan la valina, isoleucina $y$ fenilalanina, aunque también presentan valores aceptables de aminoácidos no esenciales como son, prolina, glutamato y aspartato (Ranzani \& Sturion, 1998; Capetillo Leal et al., 2010), por lo que la producción y consumo de esta especie podría mejorar la calidad nutrimental de la población local y regional.

\section{Conclusiones}

Los basidiocarpos colectados en la comunidad nativa de Korimani del centro poblado de Kiteni corresponden a la especie Pleurotus djamor (Rumph. ex Fr.) Boedijn (1959) con píleos de $9-15$ $\mathrm{cm}$, consistencia carnosa, margen lobulado con primordios y basidiomas adultos de color rosado intenso.

Se logró el desarrollo micelial en medios de cultivo alternativos determinándose estadísticamente que estos son óptimos al igual que los medios comerciales para la propagación vegetativa del micelio a una temperatura de $25{ }^{\circ} \mathrm{C}$ con una TCD de $1.1 \mathrm{~cm} /$ día, codificándose la cepa como d-027 el mismo que fue incorporado al banco de germoplasma del Centro de Investigación y Producción de Hongos Alimenticios y Medicinales CIPHAM de la Universidad Nacional de San Antonio Abad del Cusco.

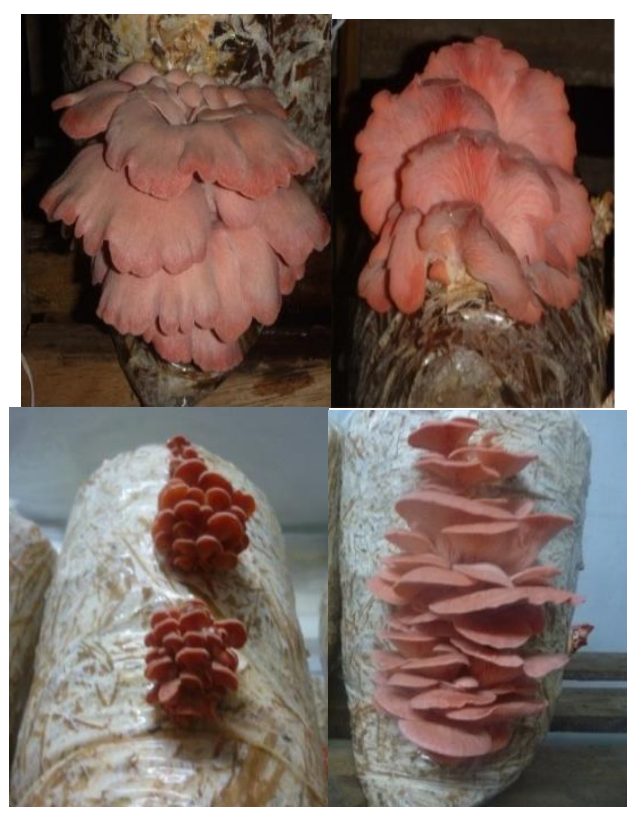

Figura 6. Basidiomas de $P$. djamor en hojas de Musa y rastrojo de Triticum.

Tabla 4. Análisis fisicoquímico de P. djamor.

\begin{tabular}{lc}
\hline Composición Nutricional (base seca) \\
Componente & Porcentaje (\%) \\
\hline Humedad & 13.52 \\
Proteína & 19.46 \\
Grasa & 2.57 \\
Ceniza & 6.74 \\
Fibra & 10.30 \\
Carbohidratos & 57.31 \\
\hline
\end{tabular}

La cepa d-027 de $P$. djamor presentó un desarrollo y crecimiento precoz, con un tiempo de formación de basidiomas de 14 a 18 días, disminuyendo ostensiblemente el tiempo de incubación y cosecha, convirtiéndose en un recurso genético fúngico promisorio para la región Cusco.

Los basidiocarpos cultivados en Musa sp. presentaron $19.46 \%$ de proteína y $57.31 \%$ de carbohidratos en base seca, resultando ser una especie con atributos potenciales para su inclusión en la biotecnología de hongos comestibles.

\section{Agradecimientos}

Agradecemos el apoyo recibido de la Dra. Genevieve Gates, de la Universidad de Tasmania que contribuyó sustancialmente a la conclusión del presente trabajo de investigación.

A los jóvenes investigadores del Centro de Investigación y Producción de Hongos Alimenticios y Medicinales (CIPHAM) por haber compartido nuestras experiencias durante el desarrollo del presente trabajo de investigación. 
A la unidad de prestaciones de servicio de análisis químico del Departamento Académico de Química de la Universidad Nacional San Antonio Abad del Cusco por los análisis fisicoquímicos realizados.

\section{Literatura citada}

Aguilar M.F. 2014. Desarrollo micelial y fructificación del hongo comestible Pleurotus eryngii (De Candolle ex Fries) Quelet. Seminario de Investigación Facultad de Ciencias Biológicas. UNSAAC. Cusco.

Buswell A.J., Cai Y.J. \& Chang S.T. 1993. Fungal-and substrate-associated factors affecting the ability of individual mushroom species to utilize different lignocellulosic growth substrates. In: Chang S.T., Buswell J.A. \& Chiu S.W. (eds). Mushroom biology and mushroom products. The Chinese University Press, Hong Kong.

Cano E. A. \& Romero B. L. 2016. Valor económico, nutricional y medicinal de hongos comestibles silvestres. Revista chilena de nutrición, 43(1). Santiago.

Capetillo Leal C.M., Sandoval Castro C.A., Cetz Zapata G. \& Ancona Méndez L. 2010. Chemical composition and amino acid profile of Pleurotus djamor and Pleurotus ostreatus cultivated in Mexico. Acta Alimentaria, 39(3).

Corner E.J.H. 1981. The agaric genera Lentinus, Panus and Pleurotus. Beih. Nova Hedwigia, 69.

Guzmán G., Montoya L., Salmones D. \& Bandala V.M. 1993. Studies on the genus Pleurotus (Badidiomycotina), II. $P$. djamor in Mexico in other Latin-american countries, taxonomic confusions, distribution and semi-industrial culture. Cryptogamic Botany, 3(2).

Guzmán G., Montoya L., Bandala V.M., Mata G., Salmones D. 1995. Studies in the genus Pleurotus, IV. Observations on the pink forms growing in México based in the interbreeding of two different strains. Mycotaxon, 53.

Guzmán G., 2000. Genus Pleurotus (Jacq.: Fr.) P. Kumm. (Agaricomycetideae): diversity, taxonomic problems, and cultural and traditional medicinal uses. Internationa Journal of Medicinal Mushrooms, 2.

Holgado M. 2012. Cultivo de Pleurotus ostreatus (Jacq.ex Fr.) Kumm y Pleurotus djamor (Rumph. ex Fr.) Boedijn (Tricholomataceae) en la comunidad San Nicolás de BariZurite-Anta. Tesis. UNSAAC.
Nicholl D.B.G. \& Petersen R.H. 2000. Phenetic plasticity in Pleurotus djamor. Mycotaxon. Ithaca Ny., 76.

Martínez C. 1993. Los hongos comestibles en México Biotecnología de su reproducción. Micología Neotropical. Revista vol. V. Escuela de post graduados de Puebla. México.

Pegler D.N. 1977. A preliminary Agaric flora of east Africa. Kew Bulletin Additional Series, 6. Kew.

Pegler D.N. 1983. Agaric flora of the Lesser Antilles. Kew Bulletin, Additional Series 9. Kew.

Pegler D.N. 1986. Agaric flora of Sri Lanka. Kew Bulletin, Aditional Series 12. Kew.

Petersen R.H. \& Hughes K.W. 1993. Intercontinental interbreeding collections of Pleurotus pulmonarius, with notes on P. ostreatus and other species. Sydowia, 45.

Ranzani L.R.T.D. \& Sturion G.L. 1998. Amino acid composition evaluation of edible mushrooms (Pleurotus spp.) cultivated on banana leaves. Archivos Latinoamericanos de Nutrición, 48(4).

Royse D. \& Sanchez J.E., 2017. Producción mundial de setas Pleurotus spp. con énfasis en países iberoamericanos. En: Sánchez J.E. \& Royse D.J. La biología, el cultivo y las propiedades nutricionales y medicinales de las setas Pleurotus spp. San Cristóbal de Las Casas, Chiapas, México: El Colegio de la Frontera Sur.

Saldarriaga O.Y. \& Pineda G.F. 2001. Manual de Micología Aplicada. Colección Ciencia y Tecnología. Editorial Universidad de Antioquia. Colombia.

Salmones D. \& Mata G. 2013. Ceparios de hongos de México. In: Sánchez J.E. \& Mata G. (eds) Hongos comestibles y medicinales en Iberoamérica: investigación y desarrollo en un entorno multicultural. El Colegio de la Frontera Sur. INECOL.

Salmones D. \& Mata G. 2015. Laccase production by Pleurotus djamor in agar media during cultivation on wheat straw. Revista Mexicana de Micología, 42.

Salmones D. \& Mata G. 2017. Recursos genéticos del género Pleurotus. En: Sánchez J.E. \& Royse D.J. La biología, el cultivo y las propiedades nutricionales y medicinales de las setas Pleurotus spp. San Cristóbal de Las Casas, Chiapas, México: El Colegio de la Frontera Sur.

Wayne W. D. 2012. Bioestadística: Base para el Análisis de las Ciencias de la Salud $4^{\circ}$ Edición.

\footnotetext{
${ }^{1}$ Universidad Nacional de San Antonio Abad del Cusco, Facultad de Ciencias, Escuela Profesional de Biología; Centro de Investigación y Producción de Hongos Alimenticios y Medicinales -CIPHAM.

${ }^{2}$ Universidad Nacional de San Antonio Abad del Cusco, Facultad de Ciencias, Escuela Profesional de Biología; Centro de Investigación y Producción de Hongos Alimenticios y Medicinales -CIPHAM.

${ }^{3}$ Universidad Nacional de San Antonio Abad del Cusco, Facultad de Ciencias, Escuela Profesional de Biología; Centro de Investigación y Producción de Hongos Alimenticios y Medicinales-CIPHAM; Sociedad Botánica del Cusco. Autor para correspondencia: mariholgado@ yahoo.es.
} 